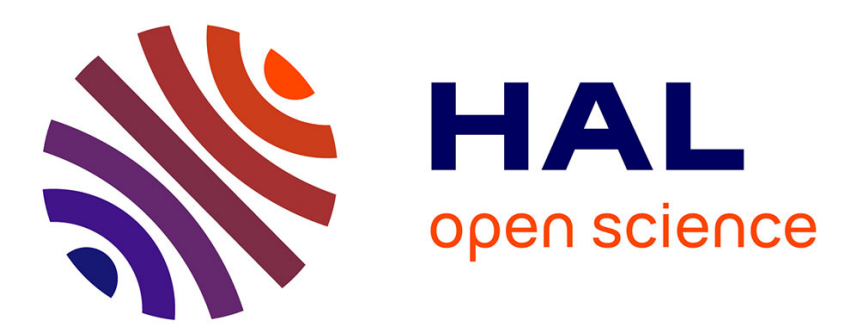

\title{
Trombe walls and green-houses : an analytical approach to long-term performances analysis
}

\author{
V. Cuomo, F. Fontana, C. Serio
}

\section{To cite this version:}

V. Cuomo, F. Fontana, C. Serio. Trombe walls and green-houses: an analytical approach to long-term performances analysis. Revue de Physique Appliquée, 1985, 20 (8), pp.589-598. 10.1051/rphysap:01985002008058900 . jpa-00245374

\section{HAL Id: jpa-00245374 https://hal.science/jpa-00245374}

Submitted on 1 Jan 1985

HAL is a multi-disciplinary open access archive for the deposit and dissemination of scientific research documents, whether they are published or not. The documents may come from teaching and research institutions in France or abroad, or from public or private research centers.
L'archive ouverte pluridisciplinaire HAL, est destinée au dépôt et à la diffusion de documents scientifiques de niveau recherche, publiés ou non, émanant des établissements d'enseignement et de recherche français ou étrangers, des laboratoires publics ou privés. 
Classification

Physics Abstracts

$44.00-86.00$

\title{
Trombe walls and green-houses : an analytical approach to long-term performances analysis
}

\author{
V. Cuomo, F. Fontana and C. Serio \\ Istituto di Fisica della Facoltà di Ingegneria, P1. Tecchio, 80125 Napoli, Italy
}

(Reçu le 15 octobre 1984, révisé le 25 février 1985, accepté le 19 avril 1985)

\begin{abstract}
Résumé. - Les caractéristiques des séquences de données de la radiation solaire, et les caractéristiques " $\mathbf{R C}$ ।» des édifices suggèrent que, la fraction de charge thermique couverte par des éléments solaires passifs peut être exprimée au moyen de simples fonctions analytiques, dont le comportement asymptotique est déterminé par les caractéristiques physiques du système.

Nous examinons les caractéristiques asymptotiques de ces fonctions, en les explicitant pour deux cas de systèmes passifs : les murs Trombe et les serres.

A l'aide des données météorologiques relatives à quelques localités Italiennes, nous calculons aussi les valeurs numériques des paramètres qui apparaissent dans les fonctions.
\end{abstract}

\begin{abstract}
Statistical properties of sequences of solar radiation data, and RC properties of buildings suggest that, the fraction of the thermal load covered by solar passive elements can be expressed by simple analytical functions, which asymptotic behaviour is determined by the physical properties of the system.

We analyse the asymptotic properties of these functions. We, then, determine their explicit expression for two cases of passive systems : Trombe walls and green-houses.

Using the meteorological data of some Italian stations, we calculate also the numerical values of the parameters.
\end{abstract}

\section{Introduction}

In the last years, the problem of calculation of performances of solar systems, and in particular that of buildings assisted by solar passive elements has been studied with many details by several authors [1-4].

The exact calculation of instantaneous performances requires complex computer simulation programs, describing in detail the structural characteristics, and thermal properties of the building. However long term performances can also be evaluated using simple analytical methods $[1,5,6]$. Such approaches are very useful in order to draw down the first design approximation of the system, i.e. the size of the various components, so that the simulation programs can be used to optimize the system, starting from configurations which are rather well designed considering both, economic and comfortness parameters.

Since these approaches require a statistical use of meteorological data, they give satisfactory results only for the calculation of long term performances of the systems.

Similar approaches have been used very successfully to calculate long term performances of several types of solar systems, as, for example, photovoltaic plants $[1,7,8]$.

In this paper, we discuss an analytical approach, which allows one to calculate monthly performances of buildings assisted by solar passive elements with a very good approximation.

In particular, we show that the monthly fraction of the «thermal needs " (load) covered by solar passive systems, can be expressed by a simple analytical function, depending on the size and conversion efficiency of the solar systems, the amount of available solar radiation and the load.

\section{Modelling of the building and choice of performance parameters.}

We only pay attention to buildings assisted by passive elements : in particular a Trombe wall and a greenhouse (Figs 1a and 1b). However, in principle, our analysis can be applied to any other passive element.

We assume that the system does not have storage 


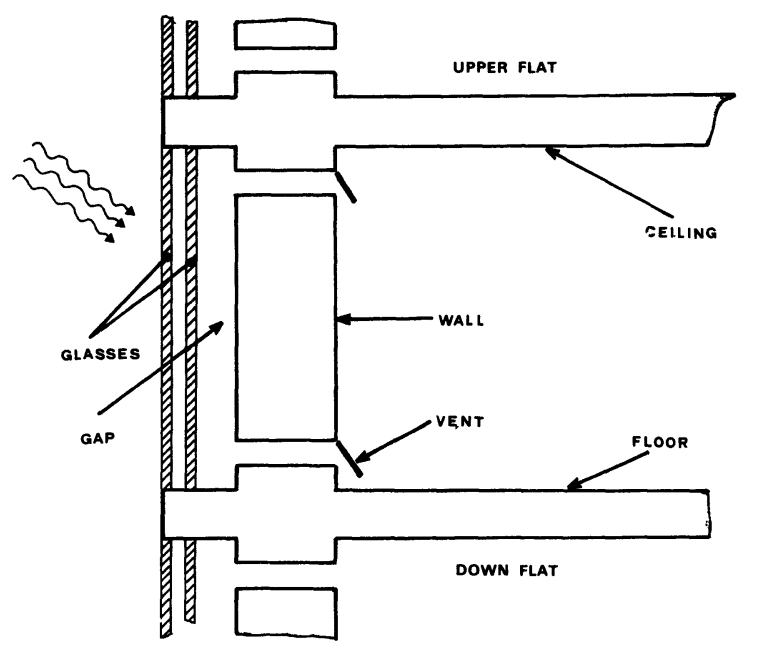

Fig. 1a. - Schematic drawing of a Trombe wall.

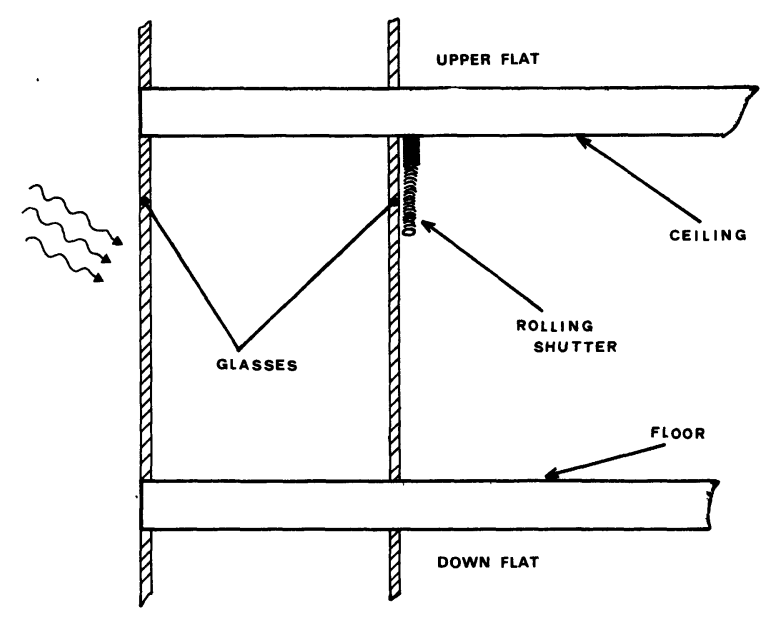

Fig. 1b. - Schematic drawing of a green-house.

units other than the building itself, i.e. : the storage unit coincides with the thermal capacity of the building.

The heating sources are the heating plant, and the incident solar radiation both on solar passive elements, and on windows. We simulate the building behaviour using the equivalence between thermal and electrical networks; the computer simulation program used is described in detail in a previous paper [4]. This program is very flexible, and can be stretched to allow one to calculate not only the dynamic thermal balance of the whole building, but also, if necessary, the dynamic thermal behaviour of any part of it. This approach allows one to control that over-heating effects do not occur in any part of the building.

With respect to the calculation of the configuration due to passive elements, we have mainly two configurations. In the first one, solar passive elements are considered as structural parts of the building. Their contribution to thermal loads is taken into account as the load differs with the situation of the actually operating passive elements and with the substituted traditional peripheral elements (e.g. a traditional wall substituting a Trombe wall). In the second case solar passive elements are simply added to the traditional building structure (e.g. a green-house added to the building). Their contribution to thermal load is the energy saved due to the addition of the passive solar element.

Such approach allows one to calculate very easily the marginal cost of solar passive elements, and to perform an economic analysis of the cost-benefict factor.

Incident solar radiation on passive elements is converted into heat, and goes to cover the heat load of the building. However it may occur, that energy converted by solar passive elements cannot be used to cover the load, and is wasted. In fact, we impose a constraint to the range of variability of the room temperature, $T_{\mathrm{a}}$, in the building : we assumed that $T_{\mathrm{a}}$ may not exceed comfortness temperature $\left(T_{\mathrm{c}}=20^{\circ} \mathrm{C}\right)$ by more than $2{ }^{\circ} \mathrm{C}$. When $T_{\mathrm{a}}>T_{\mathrm{c}}+2^{\circ} \mathrm{C}=T_{\mathrm{aM}}$ the part of the heat flux which would cause overheating effects is wasted; when $T_{\mathrm{a}}<T_{\mathrm{c}}-2^{\circ} \mathrm{C}=T_{\mathrm{am}}$ the fuel heating plant turns on in order to keep $T_{\mathrm{a}}$ in the suitable range. When $T_{\mathrm{a}}<T_{\mathrm{a} M}$, all the energy delivered by the passive elements goes to the load, and is used to cover the load and to heat the structure of the building. In our work we did not take into account active systems, nor heat storage units, different from the building itself : the converted solar radiation is stored using the thermal capacity of the building.

When the temperature of the structure is higher than the ambient temperature, and the energy flux from passive elements is not powerful enough to cover the load, the energy stored in the building structure is given back until $T_{\mathrm{a}}$ reaches $T_{\mathrm{a}}$; at this moment the heating plant is turned on. Such operating scheme is shown in figure 2.

Since thermal storage coincide with the building structures, the storage capacities are always coupled to the load. Consequently the thermal behaviour of the building is meaningfully described by its discharge time $\tau$ :

$$
\tau=\frac{1}{U_{\mathrm{L}}} \cdot C,
$$

where : $U_{\mathrm{L}}=$ complessive thermal conductance of the peripheral elements of the buildings; $C=$ thermal capacity of the whole structure. In our analysis, we restrict ourselves to the values of $\tau$ that one usually meets in Italian buildings (i.e. $15 \mathrm{~h} \leqq \tau \leqq 50 \mathrm{~h}$. In table I we show the values of $\tau$ used).

Of course the existence of a storage decouples, in part at least, the solar radiation collecting device from the utilizing device, so that the system performances should depend not only on the net amount of incident radiation, but also on time series of daily values of global radiation, i.e. on the autocorrelation coefficient [9]. For this reason we expect that the analysis of 


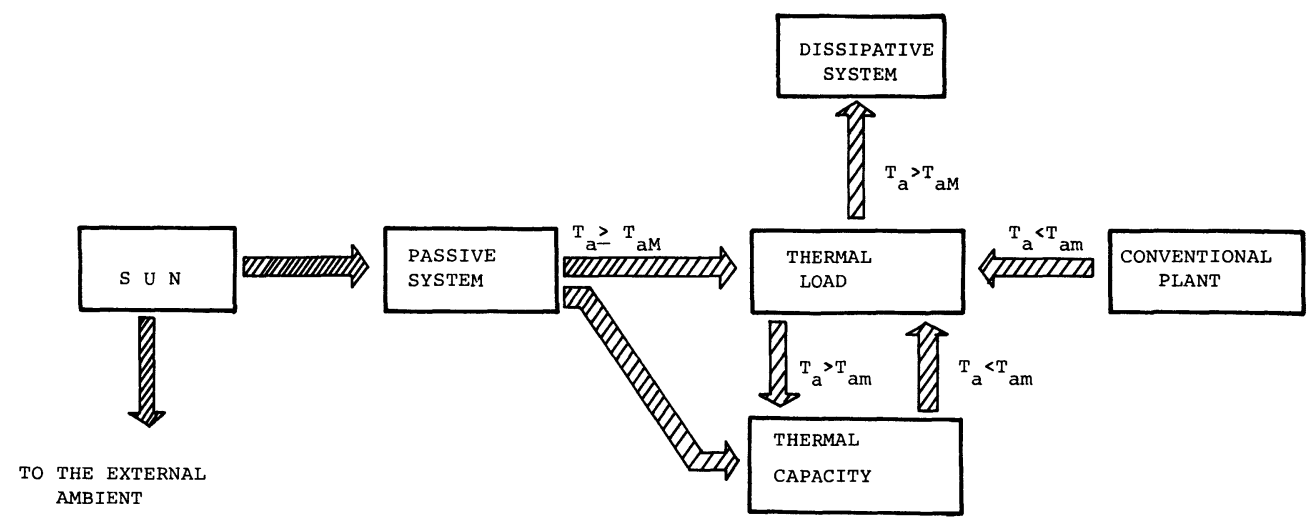

Fig. 2. - The operating scheme of the passive solar system with the constraints discussed in the paper.

Table I. - Values of the global thermal capacity $C$ $\left(\mathrm{MJ} /{ }^{\circ} \mathrm{C}\right)$ of the load $\left(U_{\mathrm{L}}\right)$ and the time constant $(\tau)$. The table shows $C$ as a function of $U_{\mathrm{L}}$ and $\tau$.

\begin{tabular}{|c|c|c|c|c|}
\hline$\underset{\left(\text { watt } /{ }^{\circ} \mathrm{C}\right)}{U_{\mathrm{L}}} \tau$ (hours) & 15 & 25 & 35 & 50 \\
\hline 150 & 8.1 & 13.5 & 18.9 & 27.0 \\
\hline 200 & 10.8 & 18.0 & 25.2 & 36.0 \\
\hline 300 & 16.2 & 27.0 & 37.8 & 54.0 \\
\hline 500 & 27.0 & 45.0 & 63.0 & 90.0 \\
\hline 1000 & 54.0 & 90.0 & 126.0 & 180.0 \\
\hline 2000 & 108.0 & 180.0 & 252.0 & 360.0 \\
\hline
\end{tabular}

the properties of daily radiation can advice us powerfully about the parametrization of performances of solar buildings.

We expect that when the time constant of the building is higher than the number of hours without radiation (i.e. at most $\tau>15$ hours, as it always occurs for building topologies in Italy) the duration of sunshine hours does not play any role in the parametrization of performances.

Moreover, we want to note that, daily radiation in clear sky conditions varies during the year. In other words, let us plot the hourly solar radiation in clear sky conditions normalized to the maximum value in the day (i.e. at noon), as a function of the distance from the sunrise normalized to the day's length; we see that the shape of the curve changes very smoothly during the year (Fig. 3). Clouds cause solar radiation down to only diffuse radiation. Since the distribution of clouds, over a long period, is generally randomly distributed [10], the general curve of normalized solar radiations vs. normalized times has the same profile as in clear sky conditions over a year, apart from some casual drops due to clouds, which amount depend of the season.

We know that the distribution of daily values of global radiation depends only on the average of

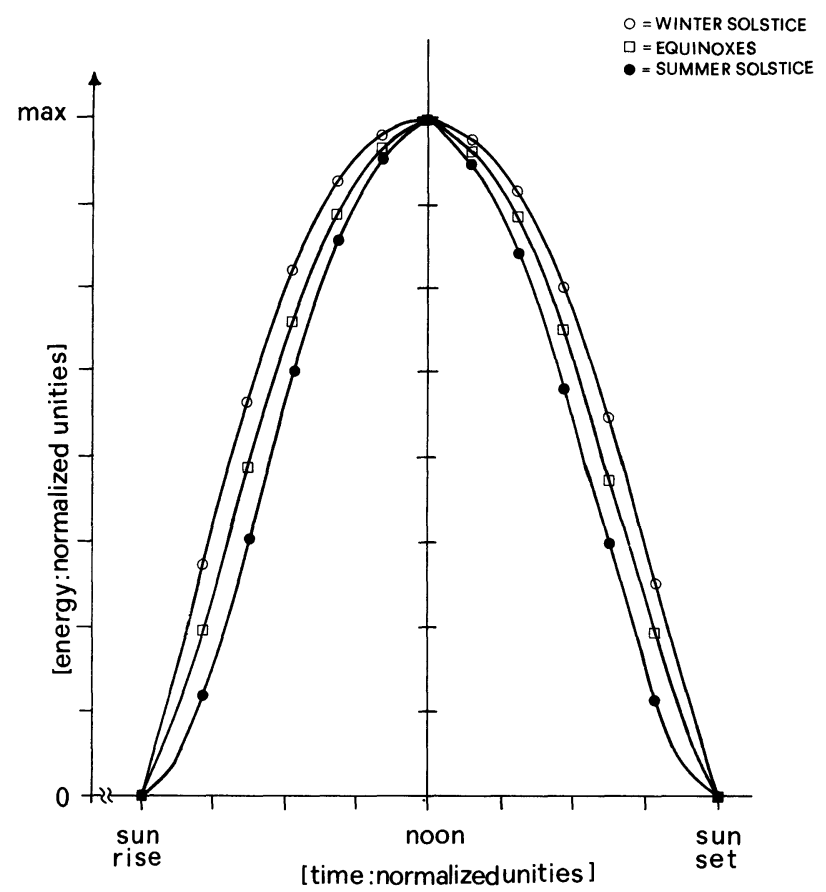

Fig. 3. - The behaviour of clear solar sky radiation vs. time in normalized unities : the impinging radiation is normalized to the midday radiation; the time is normalized to the astronomical length of the day.

monthly values [11], and that the autocorrelation coefficient is constant all over Italy and independent of seasons $[9,12]$. Since the effect of correlation does not change during the year, we expect that the main parameter is the monthly radiation average with its variance, and that the distribution of experimental values of the fraction of the load covered by the solar energy reflects the variance of data of the incident radiation.

Because of the scaling properties of solar radiation, and of the signification of $\tau$ to express structural and thermal properties of the building, we expect that the solar energy used to cover the load can be expressed in a more suitable way if we use adimensional quanti- 
ties. Consequently, we introduce the following adimensional quantities :

$$
x_{m}=\frac{E_{\mathrm{cm}}}{L_{m}}
$$

and :

$$
y_{m}=\frac{E_{\mathrm{pm}}}{L_{m}}
$$

where :

$E_{\mathrm{c} m}=$ monthly average of incident daily solar radiation on the collecting device during the $m$-th month (e.g. in Joule);

$L_{m}=$ monthly average of the daily load during the $m$-th month (e.g. in Joule);

$E_{\mathrm{p} m}=$ solar energy actually used to cover the load (monthly average of daily value in the $m$-th month).

In our case, i.e. for solar passive elements, $E_{\mathrm{c} m}$ is simply the amount of solar energy impinging on the collecting device of the system (for example the external glass in a Trombe wall); $L_{m}$ is the thermal load of the building; $E_{\mathrm{p} m}$ takes into account both, the conversion efficiency $\eta$, and the energy wasted for over-heating effects, and represents the energy which actually reaches the load. Consequently, $x_{m}$ represents the fraction of solar energy available to the system and $y_{m}$ represents the monthly fraction of the thermal load, covered by the solar passive system. Of course $y_{m}$ depends on $x_{m}$, thus :

$$
y_{m}=F_{m}\left(x_{m}\right) \quad(m=1, \ldots, 12) .
$$

Equation (3) indicates that theoretically the dependence of $y_{m}$ on $x_{m}$ can vary with the months. However, since both $y_{m}$ and $x_{m}$ are quantities normalized to the load, we suppose that the function $F_{m}$ does not depend on the month, thus :

$$
y_{m}=f\left(x_{m}\right) \quad(m=1, \ldots, 12) .
$$

Of course the function $f$, must take into account both the conversion efficiency of solar passive elements, and also the energy wasted to avoid overheating effects.

However, we can advance some hypotheses on the asymptotic behaviour of $f$. When $x_{m}$ goes to 0 , all the converted energy is used, and consequently $y_{m}$ is equal to $\eta \cdot x_{m}$ where $\eta$ is the conversion efficiency, which depends on the features of passive system used. Thus :

$$
f\left(x_{m}\right) \simeq \eta \cdot x_{m} \text { when } x_{m} \rightarrow 0
$$

in the limit of $S$ going to 0 , the energy collected by the collecting device can cover the load only during daylight hours and consequently $y_{m}$ is always lower than 1.

On the contrary, if the thermal capacity $S$ goes to the infinity, the converted energy is never wasted.
In this case, if $x_{m}$ is big enough the whole load is covered by a solar passive system thus :

$$
\lim _{\substack{x_{m \rightarrow \infty} \rightarrow \infty \\ s \rightarrow \infty}} y_{m}=1
$$

These asymptotic conditions are equivalent to those found in the case of photovoltaic plants [6]. For this reason we assume, also for the case of solar assisted building, that the following expression holds :

$$
\left(y_{m}-1\right) \cdot\left(y_{m}-\eta \cdot x_{m}\right)=\gamma
$$

where $\gamma$ is a free parameter.

In figure 4 , we summarize the discussion of this paragraph : the continuous curve represents the behaviour of $y_{m}$ if all incident energy could be used $(\eta=1$, no energy wasted in storage or avoiding over-heating effects); the dotted curve represents the behaviour of $y_{m}$ when $\eta<1$, but no part of the converted energy is wasted; the dash-dotted curves represent the actual behaviour we hypotesize for the system. In this case $A$, represents the energy losses which occur to avoid over-heating effects, and $B$ those which are consequent to the finite size of the storage, and to the storage efficiency.

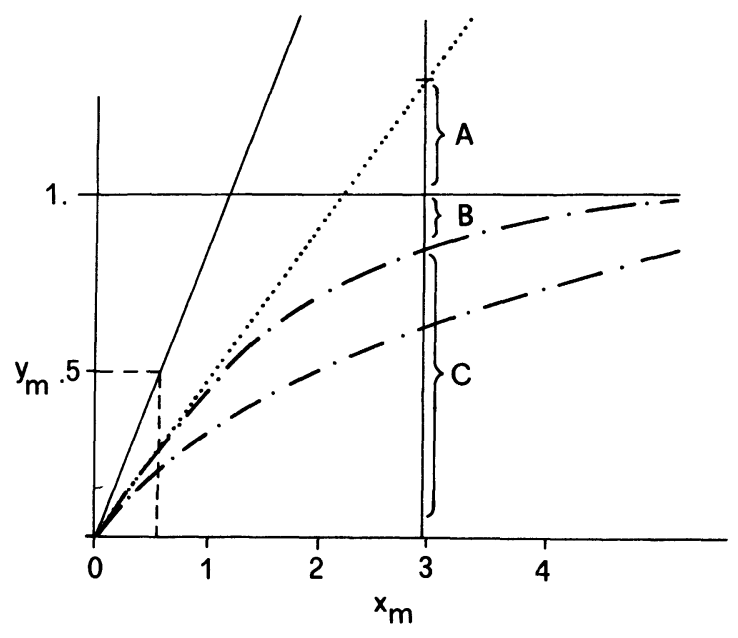

Fig. 4. - The transfer function $F$ under different conditions : continuous curve represents the case of $\eta=1$ and no dissipative equipment operating; dotted curve represents the case of $\eta<1$ and no dissipative equipment operating; dash-dotted curves represent two cases for different values of $\eta<1$ and operating dissipative equipments. $A$ is the amount of thermal energy exceeding the load; $B$ is the energy wasted because the value of $\eta$ is lower than the unity; $C$ is the energy actually used by the load.

\section{The analytical model.}

In equation (7) $\gamma$ is a free parameter mainly depeńdent on the features of the building, and on the statistical behaviour of meaningful meteorological parameters (in our analysis, the solar radiation). As already dis- 
cussed, the thermal behaviour of the building is totally described by its $\tau$. Thus, according to the results obtained for the photovoltaic systems [6], we assume :

$$
\gamma=\gamma\left(D_{m}, x_{m}, \tau\right)
$$

where $D_{m}$ is the monthly average of the day length, and $x_{m}$ is the monthly average of the ratio between the incident solar energy on the collecting devices and the load.

Of course, the expressions (7) and (8) vary, depending on the kind of solar passive system used to cover the load. We have analysed in detail, both the case of Trombe walls and of green-houses.

Since in Italian climate $\tau \geqslant 24-D_{m}$, we suppose that the expression (8) can be simplified to :

$$
\gamma=\gamma\left(x_{m}, \tau\right)
$$

In order to explain the explicit shape of equations (7) and (8), by means of simulation programs, we have simulated the behaviour of those passive systems for several kinds of buildings (i.e. for $\tau$ ranging between 15 hours, light structures, to 50 hours, heavy structures) using three years of meteorological data [13] related to three Italian localities (i.e. Genova, lat.

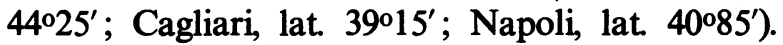

Figures 5, 6 and 7 show the equivalent electric circuits used for the simulations (their detailed description is given in Appendix). As a relevant result of our analysis, $\gamma$ comes out to be practically a constant in the given range of variation for $\tau$, and its value depends only on the kind of solar system considered. In other words, the variance of $y_{m}$ for a fixed value of $x_{m}$ can be explained by the variance of $E_{\mathrm{c} m}$ in equation (1).

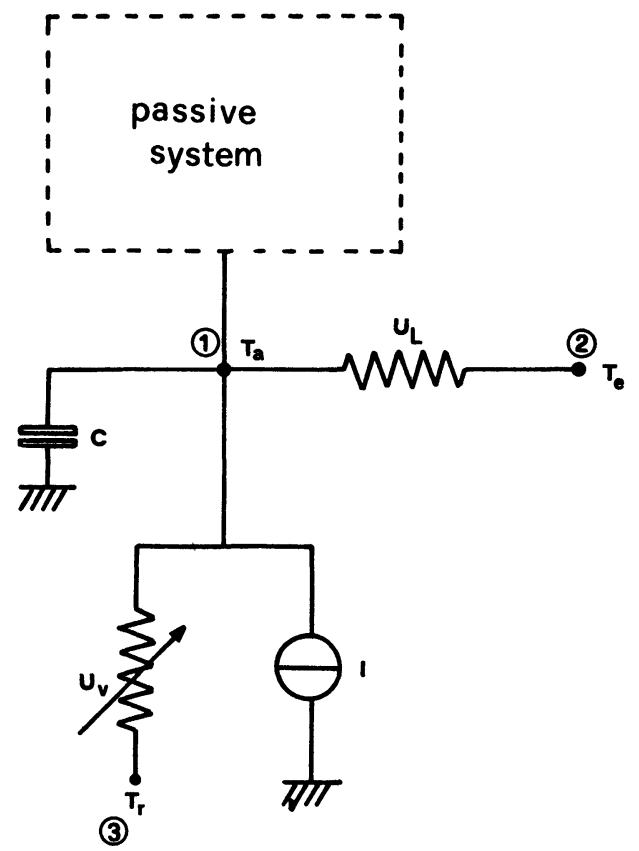

Fig. 5. - Equivalent electric circuit for a building. The circled numbers indicate the Nodes of the circuit. For a detailed discussion of the circuit see the Appendix.

In our analysis, we proceeded in the following way : first of all we calculated the best fit of the couples $\left(x_{m}, y_{m}\right)$ for each locality and each value of $\tau$. Using the $\chi^{2}$-test we found that the experimental points can be fitted by expression (7). Moreover, we found that the fits result is statistically coincident with the statistical errors, independently of the locality, and of the value of $\tau$. In figure 8, we show some

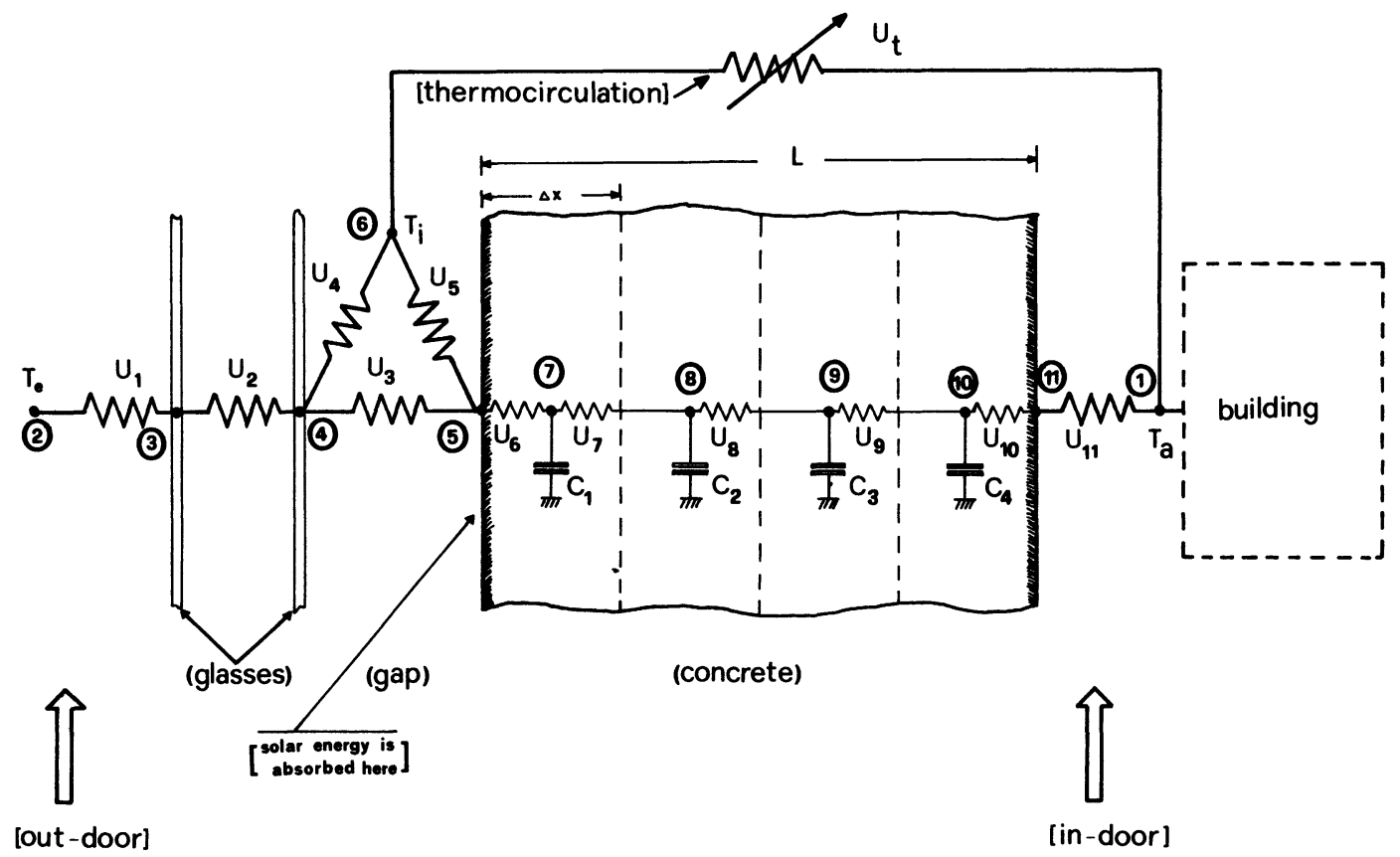

Fig. 6. - Equivalent electric circuit for a Trombe wall. The circled numbers indicate the Nodes of the circuit. For a detailed discussion of the circuit see Appendix. 


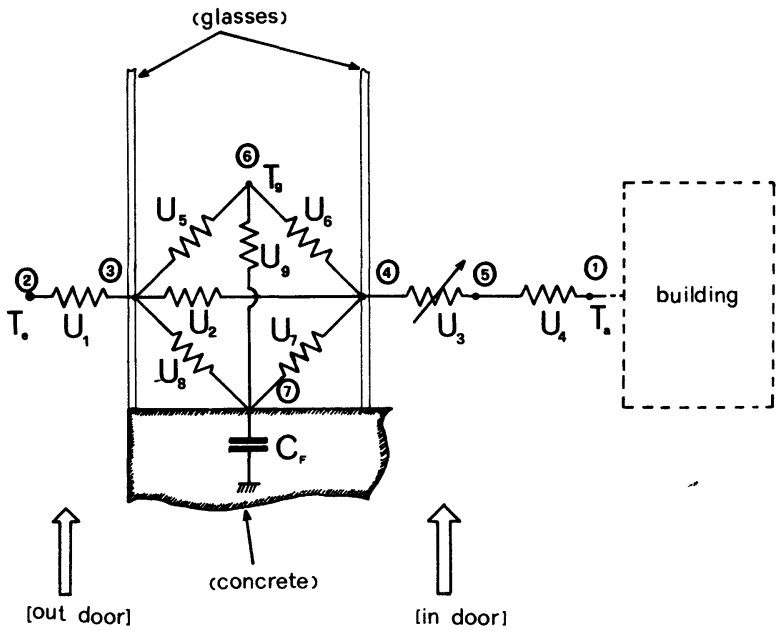

Fig. 7. - Equivalent electric circuit for a green-house. The circled numbers indicate the Nodes of the circuit. For a detailed discussion of the circuit see Appendix.

examples of the results obtained for the various localities and different values of $\tau$.

Consequently, we used all the points and calculated the best general fit curve. Using the $\chi^{2}$-test, we checked that the general fit is statistically compatible with the curves, considering single values of RC and single localities.

In figure 9, we show the experimental points (i.e. the points obtained by simulation), and the fitting curves, both for the green-house (Fig. 9a) and for the Trombe wall (Fig. 9b).
The best general fit in the case of a Trombe wall is :

$$
y_{m}=\frac{1}{2}\left[\left(x_{m}+1\right)-\sqrt{\left(x_{m}-1\right)^{2}+0.012}\right]
$$

while in the case of a green-house system, it is :

$$
y_{m}=\frac{1}{2}\left[\left(x_{m}+1\right)-\sqrt{\left(x_{m}-1\right)^{2}+0.080}\right] .
$$

We underline that, while the point of coordinates $(0,0)$ practically belongs to the curve in the case of a greenhouse system, this is not the case for a Trombe wall system. This result is not surprising : in fact greenhouse buildings are systems without threshold, since all the incident radiation is collected by the passive device. This is not the case for Trombe wall systems, in which the radiation is collected only if the outdoor temperature is high enough, i.e. sufficently higher than room temperature, to cause heat transfer towards inner rooms.

We also want to underline that the distribution of calculated points around the best fit curve depends quite completely on the statistical error introduced by the estimation of $x_{m}$.

In fact one can say :

$$
y=f(x, \eta, \gamma)
$$

since $\eta$ and $\gamma$ can be assumed as fixed parameters, once the features of the passive system fixed, one can write :

$$
y=f\left(x_{m}\right)
$$

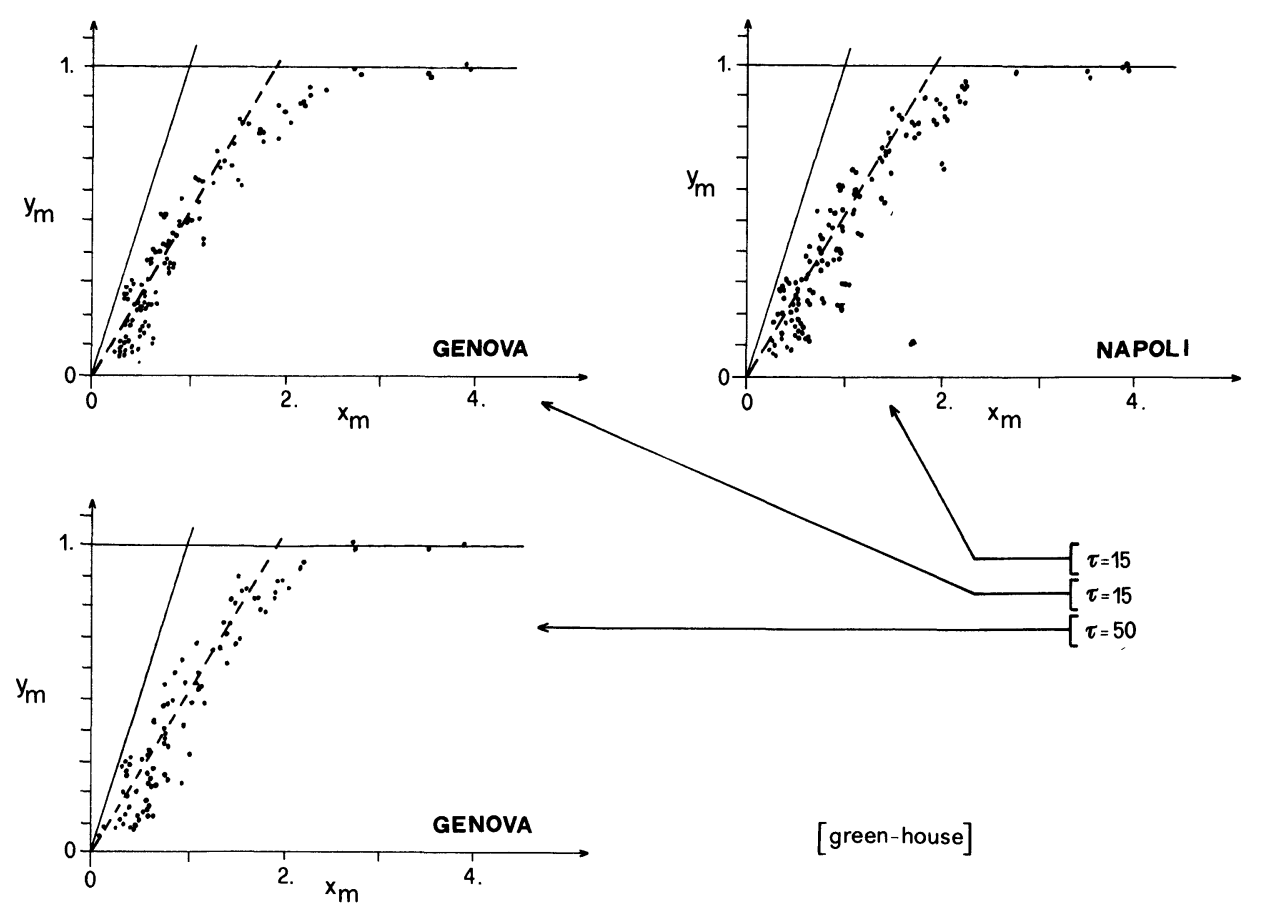

Fig. 8. - Results of the simulation for differents values of $\tau$, and different localities for a green-house system. 


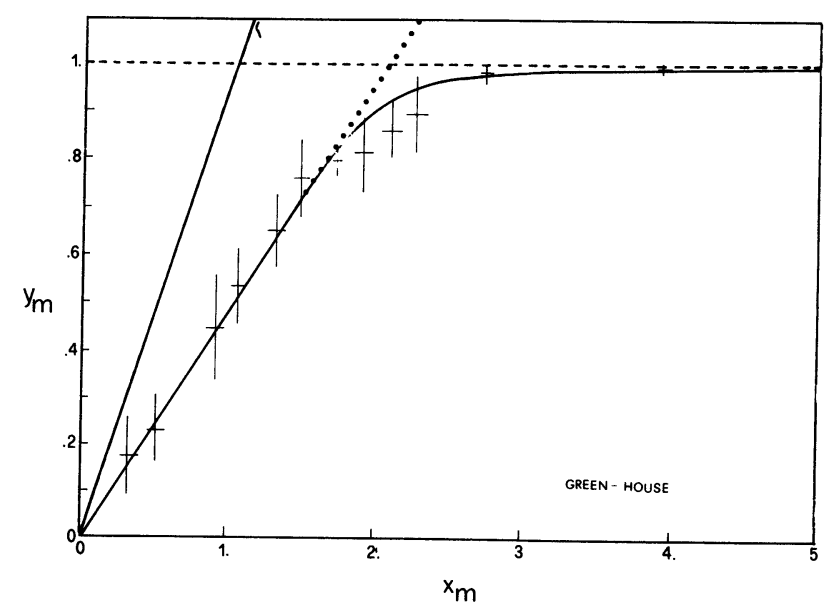

Fig. 9a. - Results of simulations (cross) and best fit curve for the green-house.

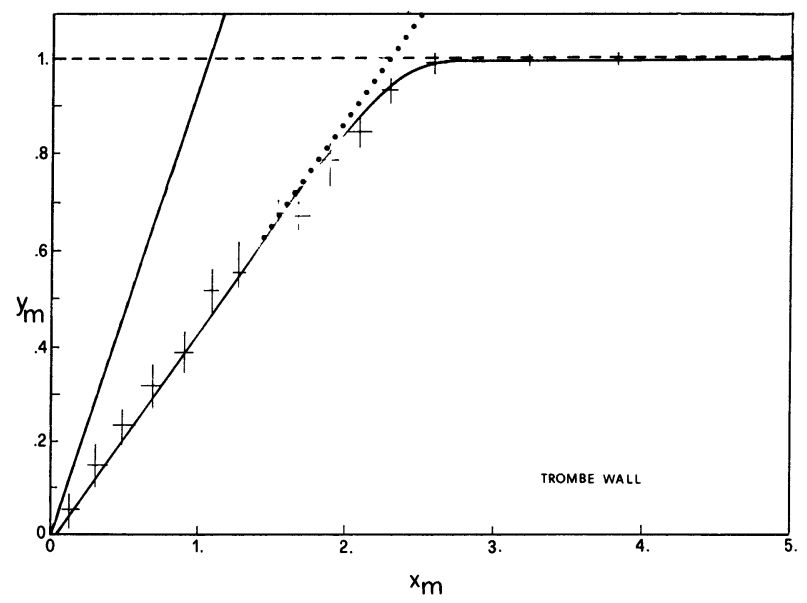

Fig. 9b. - Results of simulations (cross) and best fit curve for the Trombe wall.

where, $x_{m}$ is the average monthly value of the daily values of the solar radiation, normalized to the load. Of course such an estimation is affected by a statistical error :

$$
\Delta x_{m}=\left(\sum_{i=1}^{N} \frac{\left(x_{m i}-\langle x\rangle\right)^{2}}{N-1}\right)^{1 / 2}
$$

where, $N$ is the number of days in the $m$-th month and $\langle x\rangle$ is defined as follows :

$$
\langle x\rangle=\left(\sum_{i=1}^{N} x_{m i}\right) \frac{1}{N}
$$

and, consequently $y_{m}$ is also affected by a statistical error :

$$
\Delta y_{m}=\left|f^{\prime}\left(x_{m}\right)\right| \cdot \Delta x_{m} .
$$

Using expression (11), we have calculated the error $\Delta y_{m}$, introduced by $\Delta x_{m}$. We have found that, both for the three localities and for the two cases of passive systems, more than the $90 \%$ of the mean square deviations $\sigma_{y}$, of the points respect the best fit. This is explained by $\Delta y_{m}$.

This result allows one to conclude that the curves of $y_{m}$ towards $x_{m}$ are independent of the season and of the locality, and only depend on the type of passive solar devices used to collect and convert the incident radiation.

\section{Conclusions.}

We have analysed long-term performances of buildings which have passive solar components. We have found that, the fraction of the load covered by the solar systems can be expressed by a simple analytical function.

The asymptotic characteristic of this function can be argued using physical considerations on the statistical properties of the impinging solar radiation, and on the parameters which characterize the building in its interaction with climate.

The explicit expression of the function has been derived, both for green-houses and Trombe walls systems. The results are, for Italian climate :

$$
y_{m}=\frac{1}{2}\left[\left(x_{m}+1\right)-\sqrt{\left(x_{m}-1\right)^{2}+0.080}\right]
$$

for the green-houses and :

$$
y_{m}=\frac{1}{2}\left[\left(x_{m}+1\right)-\sqrt{\left(x_{m}-1\right)^{2}+0.012}\right]
$$

for the Trombe walls; where the numerical parameters are independent of the locality and the season.

\section{Appendix.}

In this appendix, we discuss in detail the thermal network models used for our analysis. We shall discuss separately, the part of the thermal network that refers to the solar passive elements.

BUILDING MODEL. - The thermal network simulating the building's thermal behaviour is shown in figure 5; Node 1 represents the room temperature $\left(T_{\mathrm{a}}\right)$ and Node 2 the out-door temperature $\left(T_{\mathrm{e}}\right) ; U_{\mathrm{L}}$ represents the " load" and $C$ the global thermal capacity of the building without taking into account the thermal capacities of massive parts of the solar passive elements. The current generator $I$ simulates the thermal power plant; the maximum power supplied is given by :

$$
I_{\max }=U_{\mathrm{L}} \cdot\left(T_{\mathrm{c}}-\bar{T}_{\min }\right)
$$

where :

$T_{\mathrm{c}} \quad:$ comfort temperature $\left(T_{\mathrm{c}}=20^{\circ} \mathrm{C}\right)$;

$\bar{T}_{\min }$ : designs winter temperature (i.e. average value of the minimum out-door air temperature); $U_{\mathrm{L}} \quad$ : load. 
The variable conductance $U_{v}$, and the reference temperature $T_{\mathrm{r}}$ simulate the operations requested to avoid the over-heating of the heated ambient as follows : when $T_{\mathrm{a}} \leqslant T_{\mathrm{c}}+2{ }^{\circ} \mathrm{C}$, the conductance $U_{\mathrm{v}}$ is set at zero; but if $T_{\mathrm{a}}>T_{\mathrm{c}}+2{ }^{\circ} \mathrm{C}$, then $U_{v}$ is set to the appropriate value in order to achieve the conditions of comfortness. So that the product :

$$
U_{\mathrm{v}}(t) \cdot\left(T_{\mathrm{a}}(t)-T_{0}\right) \quad(t: \text { time })
$$

gives the part of thermal energy delivered by the solar passive element that is wasted in order to avoid over-heating.

The choice of the value of $T_{\mathrm{r}}$ must satisfy the following condition :

$$
T_{\mathrm{r}}<T_{\mathrm{a}} .
$$

In our analysis $T_{\mathrm{r}}$ was setted at $0{ }^{\circ} \mathrm{C}$.

The value of $U_{\mathrm{L}}, C$ and $\tau$ (i.e. $C / U_{\mathrm{L}}$ ) used in our analysis are shown in table $I$.

TROMBE WALL MODEL. - The thermal network used to simulate the Trombe thermal behaviour is shown in figure 6. This network is quite similar to the one proposed in reference [14].

In figure 6 Nodes 1 and 2 represent respectively the room temperature $\left(T_{\mathrm{a}}\right)$, and the out-door ambient air temperature, while Node 6 represents the temperature of the air between the inner glazing (Node 4) and the outer surface of the wall (Node 5). The conductances $U_{4}, U_{5}$ and $U_{11}$ simulate convective exchanges among surfaces and air.

The conductances $U_{6}, U_{7}, U_{8}, U_{9}$ and $U_{10}$ simulate thermal conduction through concrete (Trombe wall). Their values depend on, the area $S$ of the Trombe wall surface, and on $\Delta x$ (the thickness of each one of the four layers in which the wall was subdivided in our analysis).

We have :

$$
\begin{aligned}
& U_{6}=U_{10}=\frac{\lambda \cdot S}{\Delta x / 2} \quad\left(\text { watt } /{ }^{\circ} \mathrm{C}\right) \\
& U_{7}=U_{8}=U_{9}=\frac{\lambda \cdot S}{\Delta x} \quad\left(\text { watt } /{ }^{\circ} \mathrm{C}\right)
\end{aligned}
$$

where $\lambda$ is the conductibility of the concrete (we have used $\lambda=1.28$ watt $/ \mathrm{m}^{\circ} \mathrm{C}$ ). The thermal capacities $C_{1}$, $C_{2}, C_{3}$ and $C_{4}$ simulate the mass heat capacity of the concrete. They are computed according to :

$$
C_{1}=C_{2}=C_{3}=C_{4}=\rho \cdot c \cdot S \cdot \Delta x
$$

where $\check{\rho}$ is the density $\left(\rho=2305 \mathrm{~kg} / \mathrm{m}^{3}\right)$, and $c$ is the unit heat capacity $\left(c=0.84 \mathrm{~kJ} / \mathrm{m}^{3}{ }^{\circ} \mathrm{C}\right)$ of the concrete.

$U_{1}, U_{2}$ and $U_{3}$ simulate the radiative exchanges among the parallel plane surfaces (see Fig. 6). They are computed according to :

$$
\begin{aligned}
& U_{1}=\sigma \cdot \frac{\left(T_{e}^{2}+T_{3}^{2}\right) \cdot\left(T_{e}+T_{3}\right)}{1 / \varepsilon_{e}+1 / \varepsilon_{1}-1}\left(\mathrm{watt} / \mathrm{m}^{2} \mathrm{~K}\right) \\
& U_{2}=\sigma \cdot \frac{\left(T_{3}^{2}+T_{4}^{2}\right) \cdot\left(T_{3}+T_{4}\right)}{1 / \varepsilon_{3}+1 / \varepsilon_{4}-1}\left(\mathrm{watt} / \mathrm{m}^{2} \mathrm{~K}\right) \\
& U_{3}=\sigma \cdot \frac{\left(T_{4}^{2}+T_{5}^{2}\right) \cdot\left(T_{4}+T_{5}\right)}{1 / \varepsilon_{4}+1 / \varepsilon_{5}-1}\left(\mathrm{watt} / \mathrm{m}^{2} \mathrm{~K}\right)
\end{aligned}
$$

where :

$\sigma$ : Stefan-Boltzmann constant, $5.67 \times 10^{-8}$ watt/ $\mathrm{m}^{2} \mathrm{~K}^{4}$;

$T_{3}$ : temperature of the outside glazing (Node 3 in Fig. 6);

$T_{4}$ : temperature of the inner glazing (Node 4 in Fig. 6);

$T_{5}$ : temperature of the wall outer surface (Node 5 in Fig. 6);

$\varepsilon_{i}:$ emittance of the $i$-th surface.

$U_{3}$ and $U_{2}$ include conductive term too (glass conductance : $186 \mathrm{watt} / \mathrm{m}^{2}{ }^{\circ} \mathrm{C}$ ), while $U_{1}$ includes a convective term (convective exchange between the glazing outside surface and the ambient air; we used a mean value of $23.3 \mathrm{watt} / \mathrm{m}^{2}{ }^{\circ} \mathrm{C}$ corresponding to a wind speed of $4 \mathrm{~m} / \mathrm{s})$.

Finally, $U_{t}$ simulates thermocirculation of the air from the gap between the inner glass and the wall of the room. We compute $U_{t}$ according to reference [3]

$U_{\mathrm{t}}=C \cdot A \cdot \rho_{\mathrm{a}} \cdot c_{\mathrm{a}} \cdot\left(\frac{g \cdot\left|T_{i}-T_{\mathrm{a}}\right|}{h \cdot T_{i}}\right)^{1 / 2} \quad\left(\mathrm{watt} / \mathrm{m}^{2}{ }^{\circ} \mathrm{C}\right)$

where :

$C$ : vent discharge coefficient $(C=0.8)$;

$A$ : vent opening area per unit width of the wall $\left(A=0.04 \mathrm{~m}^{2} / \mathrm{m}\right)$;

$\rho_{\mathrm{a}}:$ air density $\left(\rho=1.204 \mathrm{~kg} / \mathrm{m}^{3}\right)$;

$c_{\mathrm{a}}$ : heat capacity of the air $\left(c_{\mathrm{a}}=1006 \mathrm{~J} / \mathrm{kg}{ }^{\circ} \mathrm{C}\right)$;

$g:$ gravity acceleration $\left(g=9.8 \mathrm{~m} / \mathrm{s}^{2}\right)$;

$h$ : wall height $(h=2.8 \mathrm{~m})$.

In our analysis reverse thermocirculation was not allowed, in other words if $T_{\mathrm{a}}>T_{i}$, then $U_{\mathrm{t}}$ is set to zero.

The configurations surface and the global thickness of the Trombe wall analysed are : surface $=10,20$, $30 \mathrm{~m}^{2}$; global thichness $(l)=20,30,40 \mathrm{~cm}$. In all the analysed cases, the wall was subdivided in four layers, each one of thickness $\Delta x=l / 4$.

The stability of the numerical solutions has been discussed in reference [4].

GREEN-HOUSE. - The analysed configuration contains features of both, a typical green-house and of a direct gain system (see Fig. 1b), because this configuration is the most common for the Italian buildings.

The thermal network model used for the analysis is shown in figure 7. This circuit simulate a greenhouse with a concrete thermal storage (floor), located 
between two glasses $1 \mathrm{~m}$ apart. Node 6 in this figure, represents the air temperature in the green-house $\left(T_{\mathrm{g}}\right)$, Node 2 , the outside ambient temperature $\left(T_{\mathrm{e}}\right)$, and Node 1, the room temperature $\left(T_{\mathrm{a}}\right)$. Thermal exchanges in the green-house were modelled through three radiative conductances $\left(U_{2}, U_{7}\right.$ and $\left.U_{8}\right)$, three adductances $\left(U_{5}, U_{6}\right.$ and $\left.U_{9}\right)$ and a thermal capacity $C_{\mathrm{F}}$ that take into account the mass heat capacity of the floor (concrete). The conductance $U_{2}$ refers to the radiative exchanges between the two glasses (parallel plane surfaces) and it is computed by an expression like the equation (A.7). The conductances $U_{8}$ and $U_{7}$ describe the radiative exchanges, respectively between outer the glass-floor and the inner glass-floor (orthogonal plane surfaces), their values are computed according to reference [15].

The conductances $U_{5}, U_{6}$ and $U_{9}$ simulate the convective air exchanges in the green-house and the two glass surfaces $\left(U_{5}\right.$ and $\left.U_{6}\right)$ and the floor $\left(U_{9}\right)$.

The thermal capacity $C_{\mathrm{F}}$ is computed according to :

$$
C_{\mathrm{F}}=\rho \cdot c \cdot S_{\mathrm{F}} \cdot \Delta x
$$

where $\rho$ and $c$ are the density and the unit heat capacity of concrete, $\Delta x$ the concrete thickness (in our analysis we have assumed $\Delta x=10 \mathrm{~cm}$ ) and $S_{F}$ the area of the floor.

The conductance $U_{3}$ simulates the shadowing of the inner glass surface by means of a rolling shutter; $U_{3}$ is a variable conductance and is defined as follows :

$$
U_{3}=\left\{\begin{array}{l}
U_{v} ; \text { during diurnal hours } \\
\left(U_{v}^{-1}+U_{t}^{-1}\right)^{-1} ; \text { during nocturnal hours }
\end{array}\right.
$$

where $U_{v}$ is the conductance of glass and $U_{t}$ the conductance of rolling shutter.

Finally the conductances $U_{1}$ and $U_{4}$, take into account the convective exchanges with the air outside and in the room. They also include radiative terms of the type, given in equations (A.7); in particular,
$U_{1}$ includes a conductive term too; i.e. the conductance of the outer glass surface.

In our analysis, simulations were carried out setting alternatively the value of the area of glass surface to $10,15,20$ and $30 \mathrm{~m}^{2}$.

SOlAR RADIATION THROUGH GLASSES. - The solar flux through glasses can be written as follows :

$$
\phi(t)=\tau_{\mathrm{D}}(t) \cdot \phi_{\mathrm{D}}(t)+\tau_{\mathrm{B}}(t) \cdot \phi(t) \quad(t=\text { time })
$$

where $\tau$ is the glass transmittance of the solar radiation respectively, for diffuse $\left(\tau_{D}\right)$ and direct $\left(\tau_{B}\right)$ radiation and $\phi_{D}$ and $\phi_{B}$ are, respectively, the flux of diffuse and direct (beam) radiation.

Obviously, $\phi$ and $\tau$ depend on the characteristics of the glass and on the number of glass planes. $\phi$ and $\tau$ are time functions because, they depend on the incidence angle between the incident solar radiation and the normal to the glass surface.

In our analysis, diffuse radiation was assumed isotropic and so $\tau_{D}$ was averaged over the range $0^{\circ}$ to $90^{\circ}$; the values assumed for $\tau_{D}$ are the following : $\tau_{D}=0.75$ (for a single glass) and $\tau_{D}=0.68$ (double glass).

The function $\tau_{\mathrm{B}}(t)$, in the case of single glass and double glass is quoted in reference [1]; values of $\phi_{\mathrm{D}}(t)$ and $\phi_{\mathrm{B}}(t)$ were obtained from daily solar irradiance data on horizontal surface, using the Liu and Jordan's techniques (Ref. [1]).

In our analysis, in the case of a Trombe wall, the radiation transmitted through the double glass is assumed totally absorbed at Node 5 (Fig. 6), while in the case of a green-house, the solar radiation is totally absorbed at Node 7 (the amount of solar radiation transmitted through a single glass) and at Node 1 (direct gain; the amount of solar radiation transmitted through a double glass). These three type of solar fluxes were modelled by current generators.

\section{References}

[1] Duffie, J. A. and BeckmanN, W. A., Solar Engineering of thermal processes (John Wiley and Sons, New York) 1980.

[2] Lunde, P. J., Solar Thermal Engineering (John Wiley and Sons, New York) 1980.

[3] Initial experimental test on the use of small passive solar test-boxes to model the thermal performances of passively solar-heated building designs : GRIMMER, D. P., FARLAND, R. D. and Balcomb, J. D., Solar Energy, 22, 4 (1979) 351-354.

[4] Effects of thermal control and of passive solar elements on the dynamic behaviour of a building : Amato, U., Coluzzi, B., Cuomo, V., Serio, C. and Troise, G., Appl. Energy 17 (1984) 263-282.

REVUE DE PHYSIQUB APPLLQUGE. - T. 20, № 8, AOOT 1985
[5] Prediction of direct gain solar heating system performances : MONSEN, W. A., KLEIN, S. A. and BECKMANN, W. A., Solar Energy 27, 2 (1981) 143-147.

[6] Statistical approach to long term performances of photovoltaic systems : BARTOLI, B., CosCIA, U., CUOMO, V., Fontana, F. and Silvestrini, V., Revue Phys. Appl. 18 (5) (1983) 281-285.

[7] Dickinson, W. C. and Cherenisinoff, P. N., Solar Energy Technology Handbook (M. Dekker Inc. Butterworths, New York) 1980.

[8] Design of Photovoltaic plants : an optimization procedure : Bartoli, B., Cuomo, V., Fontana, F., Serio, C. and Silvestrini, V., Appl. Energy 18 (1984) 37-47. 
[9] Autocorrelation of daily global solar radiation: BARTOLI, B., Coluzzi, B., Cuomo, V., Francesca, M. and Serio, C., Il Nuovo Cimento 4C, 2 (1981) 113-122.

[10] Essenwanger, O., Applied Statistic in Atmospheric Science (Elsevier Scientific Publishing, Amsterdam) 1976

[11] Statistical correlation between Daily and Monthly averages of Solar Radiation Data : BARTOLI, B., Catalanotti, S., Cuomo, V., Francesca, M., Serio, C., Silvestrini, V. and Troise, G., Il Nuovo Cimento 2C (1979) 222-234.
[12] Stochastic Modelling of Solar Radiation Data : Амato U., Andretta, A., Bartoli, B., Coluzzi, B, Cuomo, V. and Serio, C., Submitted to Il Nuovo Cimento.

[13] Aereonautica Militare Italiana, Dati della rete attinometrica.

[14] Balcomb, J. D., Hedstrom, J. C. and McFarland, R. D., Passive Solar Heating of buildings : in Proceedings of the 1977 Annual Meeting of the American Section of ISES, June 6-10, 1977.

[15] Hottel, H. C. and Sarofilm, A. F.; Radiative Transfer (McGraw-Hill Book Company) 1967. 